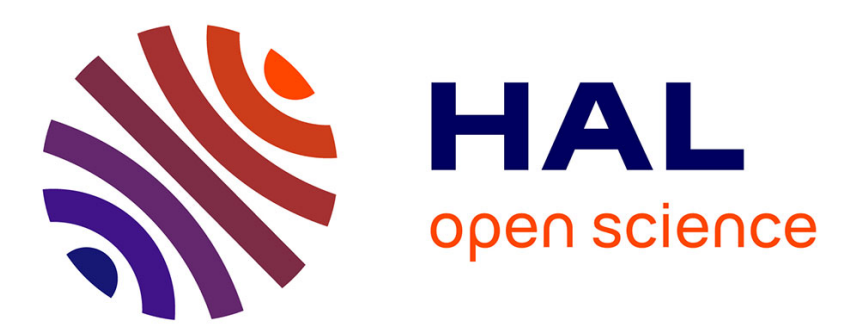

\title{
Analytical description of the injection ratio of self-biased bipolar transistors under the very high injection conditions of ESD events
}

Amaury Gendron, Philippe Renaud, Marise Bafleur, Nicolas Nolhier

\section{- To cite this version:}

Amaury Gendron, Philippe Renaud, Marise Bafleur, Nicolas Nolhier. Analytical description of the injection ratio of self-biased bipolar transistors under the very high injection conditions of ESD events. Solid-State Electronics, 2007, 52 (5), pp.663-674. hal-00382960

\section{HAL Id: hal-00382960 https://hal.science/hal-00382960}

Submitted on 11 May 2009

HAL is a multi-disciplinary open access archive for the deposit and dissemination of scientific research documents, whether they are published or not. The documents may come from teaching and research institutions in France or abroad, or from public or private research centers.
L'archive ouverte pluridisciplinaire HAL, est destinée au dépôt et à la diffusion de documents scientifiques de niveau recherche, publiés ou non, émanant des établissements d'enseignement et de recherche français ou étrangers, des laboratoires publics ou privés. 


\title{
Analytical description of the injection ratio of self-biased bipolar
}

\section{transistors under the very high injection conditions of ESD events}

\author{
A. Gendron ${ }^{1 *}$, P. Renaud ${ }^{1}$, M. Bafleur ${ }^{2}$ and N. Nohier ${ }^{2}$ \\ ${ }^{1}$ Freescale Semiconductor, 134 Av du Général Eisenhower 31023 TOULOUSE Cedex, \\ FRANCE \\ ${ }^{2}$ LAAS-CNRS, 7 Av du Colonel Roche 31077 TOULOUSE Cedex 4, FRANCE \\ ${ }^{*}$ Now at Freescale Semiconductor, 2100 E. Elliot Rd, TEMPE, AZ 85284, USA \\ Contact: philippe.Renaud@freescale.com
}

\begin{abstract}
This paper proposes a 1D-analytical description of the injection ratio of a self-biased bipolar transistor under very high current injection conditions. Starting from an expression of the current gain based on the stored charge into the emitter and base regions, we derive a new analytical expression of the current injection ratio. This analytical description demonstrates the presence of an asymptotic limit for the injection ratio at very high current densities, as the ratio of electron/hole mobilities in the case of an NPN transistor and to the ratio of hole/electron saturation velocities for a PNP. Moreover, for the first time, a base narrowing effect is demonstrated and explained in the case of a self biased PNP, in contrast with the base widening effect (Kirk effect [1]) reported for lower current density. These results are validated by numerical simulation and show a good agreement with experimental characterizations of transistors especially designed to operate under extreme condition such as Electro-Static-Discharge (ESD) events.
\end{abstract}




\section{Introduction}

Protecting high voltage smart power technologies against electrostatic discharges (ESD) is a great challenge [1] C. T. Kirk,"A theory of transistor cutoff frequency (fT) falloff at high current densities", IRE Trans. on electron devices, pp 164-173, 1961.

[2]. Typical protection structures are based on self-biased NPN bipolar transistors given their good ESD robustness. The main drawback of the NPN transistor is its strong snapback behavior [3] [4] [5], that requires stacking several structures to increase the clamping voltage above the power supply value and then fulfill the requirement of latch-up free operation [6]. To avoid stacking stacking structures, which is detrimental to both silicon area and on-state resistance, a solution consists in controlling this strong snapback effect (mostly design approach [7]) or using reduced gain PNP bipolar transistors that do not exhibit this effect [8] [9]. In both cases, a deep understanding of the involved physical mechanisms under the very high injection conditions that occurs during an ESD event is required to improve the efficiency of such protection devices.

The analytical study of the physical mechanisms involved in a bipolar transistor is a topic that has been extensively studied; with the Boltzmann approximation as a corner stone of the analytical explanation of bipolar effect. However, under very high injection condition, this approximation does not remain valid and some corrective terms need to be added. Other derivations of semiconductor devices fundamental equations may be better suited to treat the case where the current densities create a space charge approaching the doping level of a considered region.

Historically, very high injection effects were treated for current densities up to $10^{4} \mathrm{~A} . \mathrm{cm}^{-2}$, because, in most of applications, higher current densities values lead to silicon melting, hence device destruction. However, during the very short duration of an ESD event, protection devices can briefly sustain current densities as high as $10^{6} \mathrm{~A} . \mathrm{cm}^{-2}$ without destruction. Since 2 
the current peak lasts only for a few hundreds of nanoseconds, the heat generation in the protection device may not be sufficient to induce a melting of the silicon, and to damage the structure.

This paper describes the effect of such level of current densities and the impact of the resulting induced charges on the behavior of a self-biased bipolar transistor. In a self-biased configuration, base and emitter are connected or even the base can be left floating. The bias current is supplied by the avalanche current generated at the reverse biased base-collector junction (Figure 1). Starting from the same basic equations the cases of NPN and PNP will be treated separately.

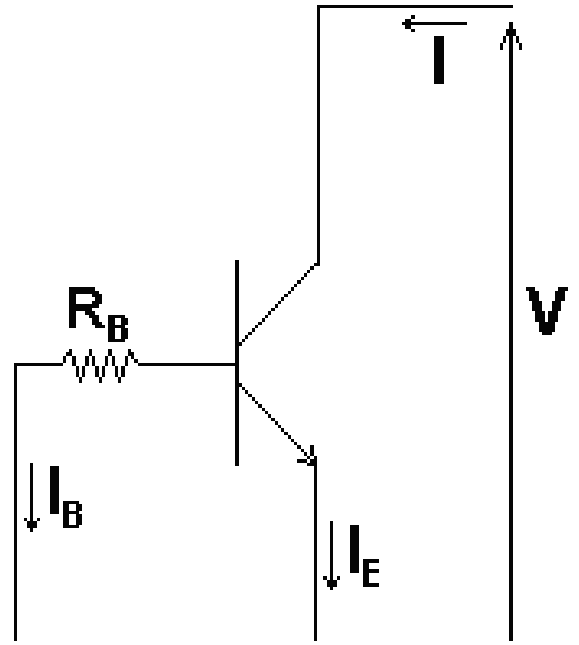

(a)

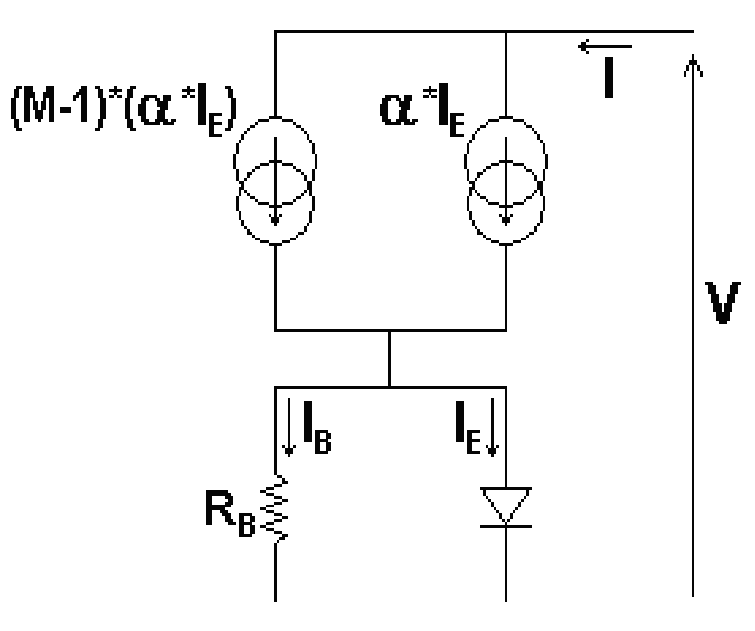

(b)

Figure 1: Configuration of a self-biased NPN bipolar (a) and its equivalent circuit (b).

\section{Theoretical consideration for the determination of current gain at very high current densities}

For the sake of simplicity, and in the aim of developing analytical models, we choose here to firstly consider a one-dimensional model of an NPN transistor in open-base configuration. This latter choice is motivated by the fact that a $1 \mathrm{D}$ approach does not allow a realistic base biasing. We also consider constant doping levels and abrupt junctions. The recombinations 
will be neglected since, in most of the advanced technologies (in particular, CMOS and smart power technologies), the emitter and base widths are much smaller than the diffusion lengths of their respective minority carriers. Finally, we will consider isothermal conditions, that means we will not take into account the self-heating of ESD protections. The implications of these simplifying hypothesis will be discussed at the end of this paper, where we will qualitatively study their effects on the results' accuracy.

The numerical applications will be based on physical parameters' values at $300 \mathrm{~K}$. In particular for the electrons and holes mobilities, respectively $\mu_{\mathrm{n}}$ and $\mu_{\mathrm{p}}$, and saturation velocities, respectively $\mathrm{v}_{\mathrm{sat}, \mathrm{n}}$ and $\mathrm{v}_{\mathrm{sat}, \mathrm{p}}$, we will use the values:

$$
\begin{aligned}
& \mu_{n B}=1417 \mathrm{~cm} \cdot \mathrm{cm}^{2} \cdot \mathrm{V}^{-1} \\
& \mu_{p B}=480 \mathrm{~cm} \cdot \mathrm{s}^{-1} \cdot V^{-1} \\
& v_{\text {sat }, n}=10.7 \mathrm{~cm} \cdot \mathrm{s}^{-1} \\
& v_{\text {sat }, p}=8.610^{6} \mathrm{~cm} \cdot \mathrm{s}^{-1}
\end{aligned}
$$

Previous studies established that the current gain $\beta$ of a bipolar transistor decreases for high current densities in the following way [10] [11] [12] :

$$
\beta=\frac{J_{C}}{J_{B}}=\frac{\beta_{0}}{1+\frac{J_{C}}{J_{H}}}
$$

Where $J_{C}$ and $J_{E}$ are respectively the collector and base current densities, $\beta_{0}$ is the well known maximal current gain expressed as:

$$
\beta_{0}=\frac{n_{i B}{ }^{2} D_{n B} N_{E} W_{E}}{n_{i E}{ }^{2} D_{p E} N_{B} W_{B}}
$$

Where $n_{i}$ is the intrinsic carrier density, $D_{n}$ and $D_{p}$ the minority carrier diffusion lengths, $N$ the doping concentration, $\mathrm{W}_{\mathrm{E}}$ and $\mathrm{W}_{\mathrm{B}}$ the emitter and base widths, respectively. Indexes $\mathrm{E}$ and $\mathrm{B}$ 4 
indicate whether the emitter or the base is considered. $\mathrm{J}_{\mathrm{H}}$ is the critical current density that can be expressed [12] with the base parameters only:

$$
J_{H}=\frac{2 q D_{n B} N_{B}}{W_{B}}
$$

Where $\mathrm{q}$ is the electron charge.

The previous analytical expressions are only valid under the assumption of a high transistor gain. That is to say the emitter injection current $\mathrm{J}_{\mathrm{e}-\mathrm{s}}$ should be much greater than the base injection current $\mathrm{J}_{\mathrm{h}+}$. However, the current gain drastically decreases with the increase in current density and the previous assumption is no more fulfilled. This is why, we propose to re-derive the basic analytical expressions by taking into account both emitter and base injection currents. This way, we should be able to describe the mechanisms involved in bipolar transistors at very low current gain values, as it is experimentally encountered during ESD events.

\section{On the Injection ratio $\underline{\mathbf{J}_{\underline{e}}} \underline{\underline{J}} \underline{\underline{\mathbf{h}}+\underline{+}}$}

Starting from the formalism and expressions set by J. P. Bailbé [13] it seems appropriate to treat the problem in terms of the total stored charges within the emitter and base. The charges are provided both by the extrinsic doping and by the current flow. This formalism leads to the following expression of the injection ratio:

$$
\gamma=\frac{J_{e-}}{J_{h+}}=\frac{\int_{E}^{B C} \frac{n}{D_{p} n_{i}^{2}} d x}{\int_{E} \frac{p}{D_{n} n_{i}^{2}} d x}=\frac{\frac{Q_{E}}{D_{p E} n_{i E}^{2}}+\frac{Q_{S B}}{D_{p B} n_{i B}^{2}}+\frac{Q_{S E}}{D_{p E} n_{i E}^{2}}}{\frac{Q_{B}}{D_{n B} n_{i B}^{2}}+\frac{Q_{S B}}{D_{n B} n_{i B}^{2}}+\frac{Q_{S E}}{D_{n E} n_{i E}^{2}}}
$$

The integral boundaries are set by the emitter contact and the transition from the base quasi- 
neutral zone to the base-collector space charge region. Hence, taking into account all different contributions, $\mathrm{Q}_{\mathrm{E}}$ is the total ionized doping charge in the emitter, $\mathrm{Q}_{\mathrm{B}}$ the total ionized doping charge in the base, $\mathrm{Q}_{\mathrm{SB}}$ the total charge induced by the electron current within the base, $\mathrm{Q}_{\mathrm{SE}}$ the total charge induced by the hole current within the emitter.

The very general expression (4) is valid for any current value. In particular, its validity domain is not limited by any current dependent assumption, such as the Boltzmann approximation, for instance.

We remind that it is important to differentiate the values of both diffusion coefficients and intrinsic carrier densities depending on whether the emitter or base is considered, as these two parameters are greatly dependant on the doping concentration.

\section{Evolution of the injection ratio under very high injection}

\section{a. Preliminary considerations}

Under very high injection, the charge $\mathrm{Q}_{\mathrm{B}}$ is negligible in comparison with the charge $\mathrm{Q}_{\mathrm{SB}}$. Thus the term depending on $\mathrm{Q}_{\mathrm{B}}$ can be systematically suppressed, and expression (4) becomes:

$$
\gamma=\frac{\frac{Q_{E}}{D_{p E} n_{i E}^{2}}+\frac{Q_{S B}}{D_{p B} n_{i B}^{2}}+\frac{Q_{S E}}{D_{p E} n_{i E}^{2}}}{\frac{Q_{S B}}{D_{n B} n_{i B}^{2}}+\frac{Q_{S E}}{D_{n E} n_{i E}^{2}}}
$$

None of the other terms can be neglected without any careful evaluation. First of all, for low injection ratio values, electron and hole currents are in the same range. Hence $\mathrm{Q}_{\mathrm{SB}}$ and $\mathrm{Q}_{\mathrm{SE}}$ are also in the same range, unless the difference between $\mathrm{W}_{\mathrm{B}}$ and $\mathrm{W}_{\mathrm{E}}$ favors the charge storage into either the emitter or the base. Besides, they should not be neglected in front of $\mathrm{Q}_{\mathrm{E}}$, to 
preserve the expression validity even at very high current.

\section{b. Generic transit time expressions}

Let us now express the different types of charges as a function of the standard transistor parameters. The determination of the charges resulting from the ionized impurities within the emitter is trivial:

$$
Q_{E}=q N_{E} W_{E}
$$

The charges induced by the current into the base and the emitter are:

$$
\begin{gathered}
Q_{S B}=\tau_{B} J_{e-} \\
Q_{S E}=\tau_{E} J_{h+}
\end{gathered}
$$

Where $\tau_{\mathrm{B}}$ and $\tau_{\mathrm{E}}$ are the transit times, respectively of the holes within the base and of the electrons within the emitter. There is not general expression of the transit times that can be analytically derived, in function of the transistor parameters. However, we can use approximated expressions under some particular operating conditions [11]:

$$
\text { For low injection condition: } \tau_{B}=\frac{W_{B}^{2}}{2 D_{n B}}
$$

$$
\text { For high injection condition: } \tau_{B}=\frac{W_{B}^{2}}{4 D_{n B}}
$$

Equivalent expressions can be derived for the transit time of the electrons within the emitter, $\tau_{\mathrm{E}}$

Expression (10) for the high injection is only valid under the high gain assumption, which is 
not the case during an ESD event. Thus, we need to derive a specific expression for the transit times that applies in our particular case.

\section{c. Hole transit time into the base}

Under very high injection conditions, the drift current into the base is no more negligible compared to the diffusion current. To take into account both the diffusion and drift currents, a method consists in defining an effective diffusion coefficient $\mathrm{D}_{\mathrm{nB} \text {,eff }}[10]$. When the low gain assumption is fulfilled, diffusion and drift currents become equal, and the resulting effective diffusion coefficient is then two times the carrier diffusion coefficient $\left(\mathrm{D}_{\mathrm{nB}, \mathrm{eff}}=2 \mathrm{D}_{\mathrm{nB}}\right)$; as exemplified in expressions (9) and (10).

Using the same methodology as developed in [10], let us recalculate the expression of this effective diffusion coefficient without neglecting the base injection current $\mathrm{J}_{\mathrm{h}+\text {. }}$.

Starting from the continuity equations:

$$
\begin{aligned}
& J_{e^{-}}=q\left(n \mu_{n B} E+D_{n B} \frac{d n}{d x}\right) \\
& J_{h_{+}}=q\left(p \mu_{p B} E-D_{p B} \frac{d p}{d x}\right)
\end{aligned}
$$

Where $\mathrm{n}$ and $\mathrm{p}$ are the electron and hole concentrations, $\frac{d n}{d x}$ and $\frac{d p}{d x}$ their respective gradients, $\boldsymbol{E}$ is the electric field within the base quasi-neutral zone. For high injection, the base neutrality implies $n=p$, thus (11) and (12) can be combined as:

$$
J_{e-}=\frac{\mu_{n B}}{\mu_{p B}} J_{h+}+q 2 D_{n B} \frac{d n}{d x}
$$


Using the definition of the injection ratio $\left(\gamma=\frac{J_{e-}}{J_{h+}}\right)$, an expression of $\mathrm{J}_{\mathrm{e}-\text { proportional to the }}$ electron gradient can be obtained:

$$
J_{e-}=q \frac{2 D_{n B}}{1-\frac{\mu_{n B}}{\mu_{p B} \gamma}} \frac{d n}{d x}
$$

This expression allows defining the effective diffusion coefficient:

$$
D_{n B, \text { effectif }}=\frac{2 D_{n B}}{1-\frac{\mu_{n B}}{\mu_{p B} \gamma}}
$$

Compared to the previous effective diffusion coefficient (equals to $2 \mathrm{D}_{\mathrm{nB}}$ ), this new expression evidences a further increase by a factor of $\frac{1}{1-\frac{\mu_{n B}}{\mu_{p B} \gamma}}$. This anticipates that drift current becomes the dominant conduction type with respect to diffusion current.

Using (7), the electron transit time within the base becomes:

$$
\tau_{B}=\frac{\left(1-\frac{\mu_{n B}}{\mu_{p B} \gamma}\right) W_{B}^{2}}{4 D_{n B}}
$$

And the base current induced charge:

$$
Q_{S B}=\frac{\left(1-\frac{\mu_{n B}}{\mu_{p B} \gamma}\right) W_{B}^{2} J_{e-}}{4 D_{n B}}
$$




\section{d. Electron transit time into the emitter}

The determination of the electron transit time within the emitter is not as straightforward. Since the emitter doping level can be rather high, the high injection condition may not be satisfied over the full duration of the ESD pulse. In particular, the approximation $n=p$ cannot be applied, in the same way as previously done for the base. Regarding the emitter, both low and high injection conditions can be encountered during an ESD event. As previously mentioned, a unique transit time analytical expression cannot be determined. Then, there is no way to have a precise analytical description of the effects resulting from the current induced charge into the emitter $\mathrm{Q}_{\mathrm{SE}}$. However, most bipolar transistors used as ESD protections, exhibit a base that is significantly wider than the emitter, making possible to neglect $\mathrm{Q}_{\mathrm{SE}}$ compared to $\mathrm{Q}_{\mathrm{SB}}$. Using this new condition on the emitter and base dimensions, an injection ratio expression without the $\mathrm{Q}_{\mathrm{SE}}$ terms can be derived from expression (5):

$$
\gamma=\frac{\frac{Q_{E}}{D_{p E} n_{i E}^{2}}+\frac{Q_{S B}}{D_{p B} n_{i B}^{2}}}{\frac{Q_{S B}}{D_{n B} n_{i B}^{2}}}
$$

This expression will be preferentially considered in the following.

Besides, we can take advantage of expression (5) to give a rough evaluation of the impact of $\mathrm{Q}_{\mathrm{SE}}$ on the injection ratio. Two values of $\mathrm{Q}_{\mathrm{SE}}$ should be considered, one under low injection and high gain conditions with transit time expression (9):

$$
Q_{S E}=\frac{W_{E}^{2}}{2 D_{p E}} J_{h+}
$$

and one under high injection and low gain conditions with transit time expression (10) : 


$$
Q_{S E}^{\prime}=\frac{Q_{S E}}{2}
$$

As the purpose is only to determine the magnitude of the modification induced on the injection ratio, it is not worthwhile to make a more complex computation under high injection and low gain conditions.

\section{e. Injection ratio expression}

First, the current induced charge into the emitter $\mathrm{Q}_{\mathrm{SE}}$ is not taken into account. The computation is based on expression (18). By inserting expressions (6) and (17) of $\mathrm{Q}_{\mathrm{E}}$ and $\mathrm{Q}_{\mathrm{SB}}$, respectively, we obtain:

$$
\gamma=\frac{\frac{q N_{E} W_{E}}{D_{p E} n_{i E}^{2}}+\frac{\left(1-\frac{\mu_{n B}}{\mu_{p B} \gamma}\right) W_{B}^{2} J_{e-}}{4 D_{n B} D_{p B} n_{i B}^{2}}}{\frac{\left(1-\frac{\mu_{n B}}{\mu_{p B} \gamma}\right) W_{B}^{2} J_{e-}}{4 D_{n B}^{2} n_{i B}^{2}}}
$$

This expression can be re-written as:

$$
\gamma=\frac{2 J_{C r}}{\left(1-\frac{\mu_{n B}}{\mu_{p B} \gamma}\right) J_{e-}}+\frac{\mu_{n B}}{\mu_{p B}}
$$

Where the parameter $\mathrm{J}_{\mathrm{Cr}}$, homogenous to a current density, is expressed as:

$$
J_{C r}=\frac{2 q D_{n B}^{2} n_{i B}^{2} N_{E} W_{E}}{D_{p E} n_{i E}^{2} W_{B}^{2}}
$$

The factorization of $\gamma$ in (22) leads to the following second degree equation: 


$$
\gamma^{2}-2\left(\frac{\mu_{n B}}{\mu_{p B}}+\frac{J_{C r}}{J_{e-}}\right) \gamma+\left(\frac{\mu_{n B}}{\mu_{p B}}\right)^{2}=0
$$

The reduced determinant of the corresponding binomial is:

$$
\Delta^{\prime}=\left(\frac{\mu_{n B}}{\mu_{p B}}+\frac{J_{C r}}{J_{e-}}\right)^{2}-\left(\frac{\mu_{n B}}{\mu_{p B}}\right)^{2}=\frac{J_{C r}}{J_{e-}}\left(2 \frac{\mu_{n B}}{\mu_{p B}}+\frac{J_{C r}}{J_{e-}}\right)>0
$$

The reduced determinant is positive; equation (24) has then two mathematical solutions. One solution increases with the electron current and has no physical meaning in our study, thus only the decreasing solution is valid:

$$
\gamma=\frac{J_{C r}}{J_{e-}}+r_{1}+\sqrt{\left[\frac{J_{C r}}{J_{e-}}+r_{1}\right]^{2}-r_{1}^{2}}
$$

With:

$$
r_{1}=\frac{\mu_{n B}}{\mu_{p B}}
$$

Expression (26) shows that a modification of the behavior occurs when $\frac{J_{C r}}{J_{e_{-}}}$becomes close to the mobility ratio $r_{1}$. Then, $\mathrm{J}_{\mathrm{Cr}}$ can be considered as a critical current density to which $\mathrm{J}_{\mathrm{e}-}$ has to be compared to characterize the injection ratio variations. To evaluate $\mathrm{J}_{\mathrm{Cr}}$, expression (23) can be re-written as:

$$
J_{C r}=\gamma_{0} J_{H}
$$

Where $\mathrm{J}_{\mathrm{H}}$ is the critical current density describing the beginning of the gain fall, given by (3), 
and $\gamma_{0}$ the same expression as the maximum injection ratio at low injection:

$$
\gamma_{0}=\frac{D_{n B} n_{i B}^{2} N_{E} W_{E}}{D_{p E} n_{i E}^{2} N_{B} W_{B}}
$$

The trend of the injection ratio versus the normalized electron current $\left(\mathrm{J}_{\mathrm{e}} / \mathrm{J}_{\mathrm{Cr}}\right)$ is plotted in Figure 2. At $300 \mathrm{~K}, \mathrm{r}_{1}$, the ratio of the electrons mobility on the holes one, is equal to 3.0.

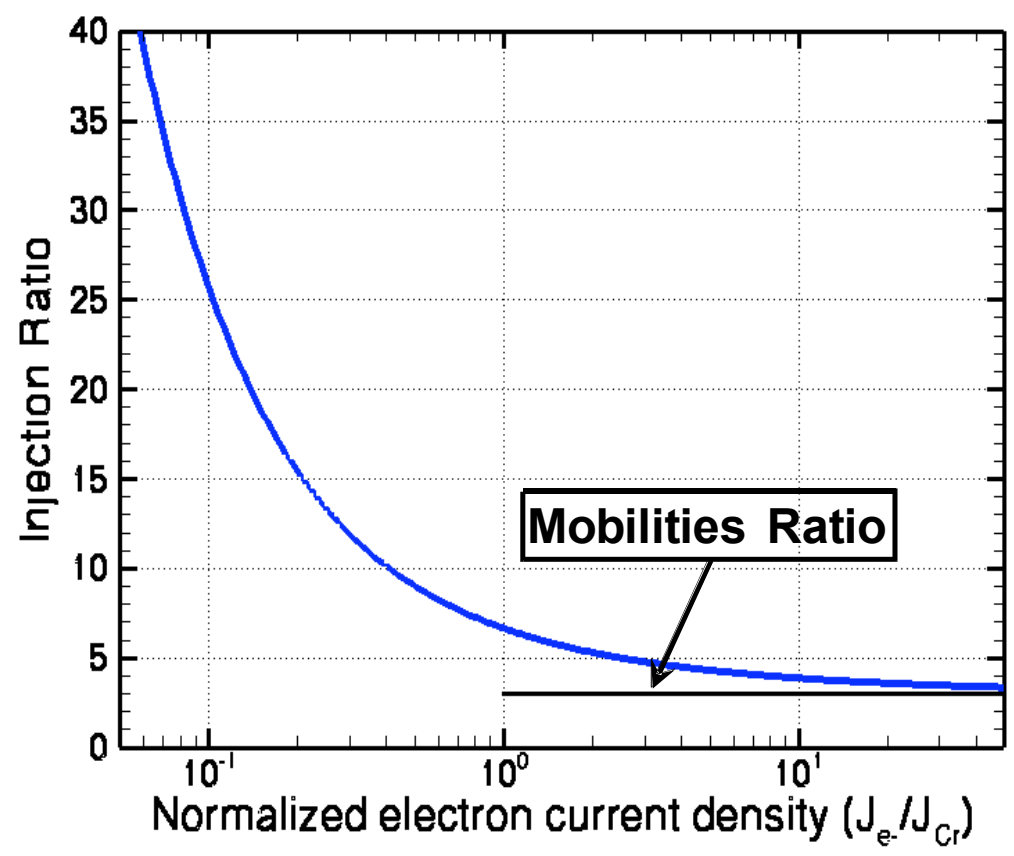

Figure 2: Injection ratio versus normalized electron current drawn from (26).

\section{f. Asymptotic behavior at extreme high injection}

For $\mathrm{J}_{\mathrm{e}-}>>\mathrm{J}_{\mathrm{Cr}}$, the injection ratio expression (26) has an asymptotic minimum limit equal to the mobility ratio:

$$
\gamma_{l}=r_{1}
$$

A simple manipulation of expression (5), in which $\mathrm{Q}_{\mathrm{SE}}$ is neglected, allows analyzing the physical mechanisms associated with this asymptotic behavior: 


$$
\gamma=\frac{\frac{Q_{E}}{D_{p E} n_{i E}^{2}}+\frac{Q_{S B}}{D_{p B} n_{i B}^{2}}}{\frac{Q_{S B}}{D_{n B} n_{i B}^{2}}}=\frac{\frac{Q_{E}}{D_{p E} n_{i E}^{2}}}{\frac{Q_{S B}}{D_{n B} n_{i B}^{2}}}+r_{1}
$$

With this expression, it is obvious that the injection ratio reaches its asymptotic limit when the current induced charge within the base becomes greater than the doping charge within the emitter $\left(\mathrm{Q}_{\mathrm{SB}}>>\mathrm{Q}_{\mathrm{E}}\right)$. Considering (11) and (12) continuity equations when $\mathrm{n}=\mathrm{p}$, an injection ratio limit equal to the mobility ratio could only be reached if, for both electron and hole currents within the base, the drift current due to the electric field becomes dominant compared to the diffusion current.

This result has an important implication since, until today, it has been considered that under high injection conditions, the drift current reaches only the value of the diffusion current. To our knowledge, it has never been ever reported that for extreme high injection conditions, the drift current could be the main component of a bipolar transistor current.

We should outline that we do not know at the present stage of the study if this limit can be achieved. As $\mathrm{J}_{\mathrm{Cr}}$ depends on the current density, via the modification of the internal base width $\mathrm{W}_{\mathrm{E}}$ under high injection, we are not sure that the condition $\mathrm{J}_{\mathrm{e}-}>>\mathrm{J}_{\mathrm{Cr}}$ can be fulfilled. Further investigations on that aspect will be performed in the following of the paper.

\section{g. Evaluation of $Q_{S E}$ contribution}

The purpose is to determine the corrective terms in the injection ratio expression (26), when $\mathrm{Q}_{\mathrm{SE}}$ is taken into account. As stated before, there is no analytical expression of $\mathrm{Q}_{\mathrm{SE}}$ valid over the full duration of the ESD stress and we will only make a rough evaluation of its contribution.

At first, the low injection within the emitter is considered. By inserting expressions (6), (17) 
and (19) into the injection ratio expression (5), we obtain:

$$
\gamma=\frac{\frac{q N_{E} W_{E}}{D_{p E} n_{i E}^{2}}+\frac{\left(1-\frac{\mu_{n B}}{\mu_{p B} \gamma}\right) W_{B}^{2} J_{e-}}{4 D_{n B} D_{p B} n_{i B}^{2}}+\frac{W_{E}^{2} J_{h+}}{2 D_{p E}^{2} n_{i E}^{2}}}{\frac{\left(1-\frac{\mu_{n B}}{\mu_{p B} \gamma}\right) W_{B}^{2} J_{e-}}{4 D_{n B}^{2} n_{i B}^{2}}+\frac{W_{E}^{2} J_{h+}}{2 D_{n E} D_{p E} n_{i E}^{2}}}
$$

As previously done when $\mathrm{Q}_{\mathrm{SE}}$ was neglected, similar mathematical manipulations lead to a new expression of the injection ratio:

$$
\gamma=\frac{J_{C r}}{J_{e-}}+\left(r_{1}-r_{E 1}\right)+\sqrt{\left[\frac{J_{C r}}{J_{e-}}+\left(r_{1}-r_{E 1}\right)\right]^{2}-r_{1}^{2}+r_{E 2}}
$$

Where $\mathrm{r}_{\mathrm{E} 1}$ and $\mathrm{r}_{\mathrm{E} 2}$ are two parameters without dimensions given by:

$$
\begin{gathered}
r_{E 1}=\frac{D_{n B}^{2} n_{i B}^{2} W_{E}^{2}}{D_{n E} D_{p E} n_{i E}^{2} W_{B}^{2}} \\
r_{E 2}=\frac{2 D_{n B}^{2} n_{i B}^{2} W_{E}^{2}}{D_{p E}^{2} n_{i E}^{2} W_{B}^{2}}
\end{gathered}
$$

This expression of the injection ratio still exhibits an asymptotic limit when $\mathrm{J}_{\mathrm{e}-}>>\mathrm{J}_{\mathrm{Cr}}$ :

$$
\gamma_{l}=\left(r_{1}-r_{E 1}\right)+\sqrt{\left(r_{1}-r_{E 1}\right)^{2}-r_{1}^{2}+r_{E 2}}
$$

To evaluate the effect of $Q_{\mathrm{SE}}$, we should compare $\mathrm{r}_{\mathrm{E} 1}$ to $\mathrm{r}_{1}$ and $\mathrm{r}_{\mathrm{E} 2}$ to $\mathrm{r}_{1}{ }^{2}$. This effect can be neglected if: 


$$
\left\{\begin{array}{l}
r_{E 1}<<r_{1} \\
r_{E 2}<<r_{1}^{2}
\end{array}\right.
$$

Besides, the coefficients $\mathrm{r}_{\mathrm{E} 1}$ and $\mathrm{r}_{\mathrm{E} 2}$ are proportional to $\left(\frac{W_{E}}{W_{B}}\right)^{2}$, which confirms that $\mathrm{Q}_{\mathrm{SE}}$ is negligible for a base significantly wider than the emitter.

Regarding the case of high injection with low gain, the study shows that the terms $\mathrm{r}_{\mathrm{E} 1}$ and $\mathrm{r}_{\mathrm{E} 2}$ should be divided by two. The injection ratio is then given by:

$$
\gamma=\frac{J_{C r}}{J_{e-}}+\left(r_{1}-\frac{r_{E 1}}{2}\right)+\sqrt{\left[\frac{J_{C r}}{J_{e-}}+\left(r_{1}-\frac{r_{E 1}}{2}\right)\right]^{2}-r_{1}^{2}+\frac{r_{E 2}}{2}}
$$

This reduction of the corrective terms is due to the decrease of the transit time at high injection, which leads to lower charge $\mathrm{Q}_{\mathrm{SE}}$.

In this case, the asymptotic limit for $\mathrm{J}_{\mathrm{e}_{-}->}>\mathrm{J}_{\mathrm{Cr}}$ is given by:

$$
\gamma=\left(r_{1}-\frac{r_{E 1}}{2}\right)+\sqrt{\left(r_{1}-\frac{r_{E 1}}{2}\right)^{2}-r_{1}^{2}+\frac{r_{E 2}}{2}}
$$

\section{Application to a self-biased bipolar transistor during an ESD stress.}

\section{a. On-state resistance ( $\left.R_{O N}\right)$ of an ESD protection}

The on-state resistance, $\mathrm{R}_{\mathrm{ON}}$, is one of the most critical parameters of an ESD protection; as it must be sufficiently low to prevent over voltage reaching oxide breakdown. For a protection based on a self-biased bipolar transistor, the $\mathrm{R}_{\mathrm{ON}}$ results mainly from high current effects at the base-collector junction [8]. The charge induced by the current adds up to the base doping, 
which is virtually higher, and subtracts to the collector doping, which becomes virtually lower [1]. This modulation of the space charge region (SCR) leads to a field modification resulting in an equivalent resistance. During an ESD stress, the current induced charge in the SCR could reach $10^{18} \mathrm{~cm}^{-3}$. In smart power technologies, the doping levels encountered are lower or in the range of this value, meaning that these high injection effects have a significant impact.

Calculation of the current induced charge in the SCR indirectly leads to an estimate of the SCR width variation and of the voltage drop in this region, if we consider:

- The maximum value of the electric field at the base-collector junction approximately constant with current.

- An abrupt collector-base junction with a collector doping level much higher than the base one to approximate a static junction position.

- The current induced charge within the base is much higher than the doping charge.

These conditions are not too restrictive, in particular for high voltage ESD protection. By this way, we can determine a first approximation of the $\mathrm{R}_{\mathrm{ON}}$ variations without developing an analytical expression for the SCR width.

\section{b. Current induced charge in the base-collector SCR}

Within the SCR, the carriers reach their saturation velocity. Thus, the electrons $n$ and holes $p$ concentrations in the region can be expressed as:

$$
n=\frac{J_{e-}}{q v_{s a t, n}}
$$




$$
p=\frac{J_{h+}}{q v_{s a t, p}}
$$

The resulting total charge within the SCR becomes:

$$
\rho_{c s r}=\frac{J_{h+}}{v_{s a t, p}}-\frac{J_{e-}}{v_{s a t, n}}
$$

Using $\mathrm{J}=\mathrm{J}_{\mathrm{e}_{-}}+\mathrm{J}_{\mathrm{h}+}$, equation (42) can be expressed as a function of the total current $\mathrm{J}$ :

$$
\rho_{s c r}=\frac{1}{v_{s a t, p}} J-\left(\frac{1}{v_{s a t, n}}+\frac{1}{v_{s a t, p}}\right) J_{e-}
$$

An analytical expression of $J_{e_{-}}$as a function of $\mathrm{J}$ can be extracted by using $\mathrm{J}=\mathrm{J}_{\mathrm{e}^{-}}+\mathrm{J}_{\mathrm{h}+}$ and $\gamma=\frac{J_{e-}}{J_{h+}}$

$$
\gamma=\frac{J_{e-}}{J-J_{e-}}
$$

By combining it with the expression (26) of the injection ratio, we obtain a second order equation in $\mathrm{J}_{\mathrm{e}-}$ :

$$
r_{1}^{2}\left(J-J_{e-}\right)^{2}-2\left(J-J_{e-}\right)\left(r_{1} J_{e-}+J_{C r}\right)+J_{e-}^{2}=0
$$

whose solution is:

$$
J_{e-}=\frac{r_{1}\left(1+r_{1}\right) J_{-} J_{C r}+\sqrt{2\left(1+r_{1}\right) J_{C r} J+J_{C r}^{2}}}{\left(1+r_{1}\right)^{2}}
$$

Inserting expression (46) into (43), we obtain an analytical expression of the SCR charge versus the total current density $\mathrm{J}$ : 


$$
\rho_{s c r}=\frac{1}{v_{s a t, p}} J-\left(\frac{1}{v_{s a t, n}}+\frac{1}{v_{s a t, p}}\right) \frac{r_{1}\left(1+r_{1}\right) J_{-} J_{C r}+\sqrt{2\left(1+r_{1}\right) J_{C r} J+J_{C r}^{2}}}{\left(1+r_{1}\right)^{2}}
$$

\section{c. Variations of the current induced charge in the base-collector SCR}

To plot the evolution of $\rho_{\mathrm{SCR}}$, it is convenient to consider a value normalized on a critical charge $\rho_{\mathrm{Cr}}$ defined as:

$$
\rho_{C r}=J_{C r}\left(\frac{1}{v_{s a t, n}}+\frac{1}{v_{s a t, p}}\right)
$$

From (47), it is straightforward to obtain the expression of this normalized value of $\rho_{\mathrm{SCR}}$ :

$$
\frac{\rho_{s c r}}{\rho_{C r}}=r_{2} \frac{J}{J_{C r}}-\frac{r_{1}\left(1+r_{1}\right) \frac{J}{J_{C r}}-1+\sqrt{2\left(1+r_{1}\right) \frac{J}{J_{C r}}+1}}{\left(1+r_{1}\right)^{2}}
$$

With

$$
r_{2}=\frac{v_{s a t, n}}{v_{s a t, n}+v_{s a t, p}}
$$

The trend of the $\rho_{\mathrm{SCR}}$ normalized on $\rho_{\mathrm{Cr}}$ versus the current density normalized on $\mathrm{J}_{\mathrm{Cr}}$ is plotted in Figure 3, both for a NPN and a PNP. 


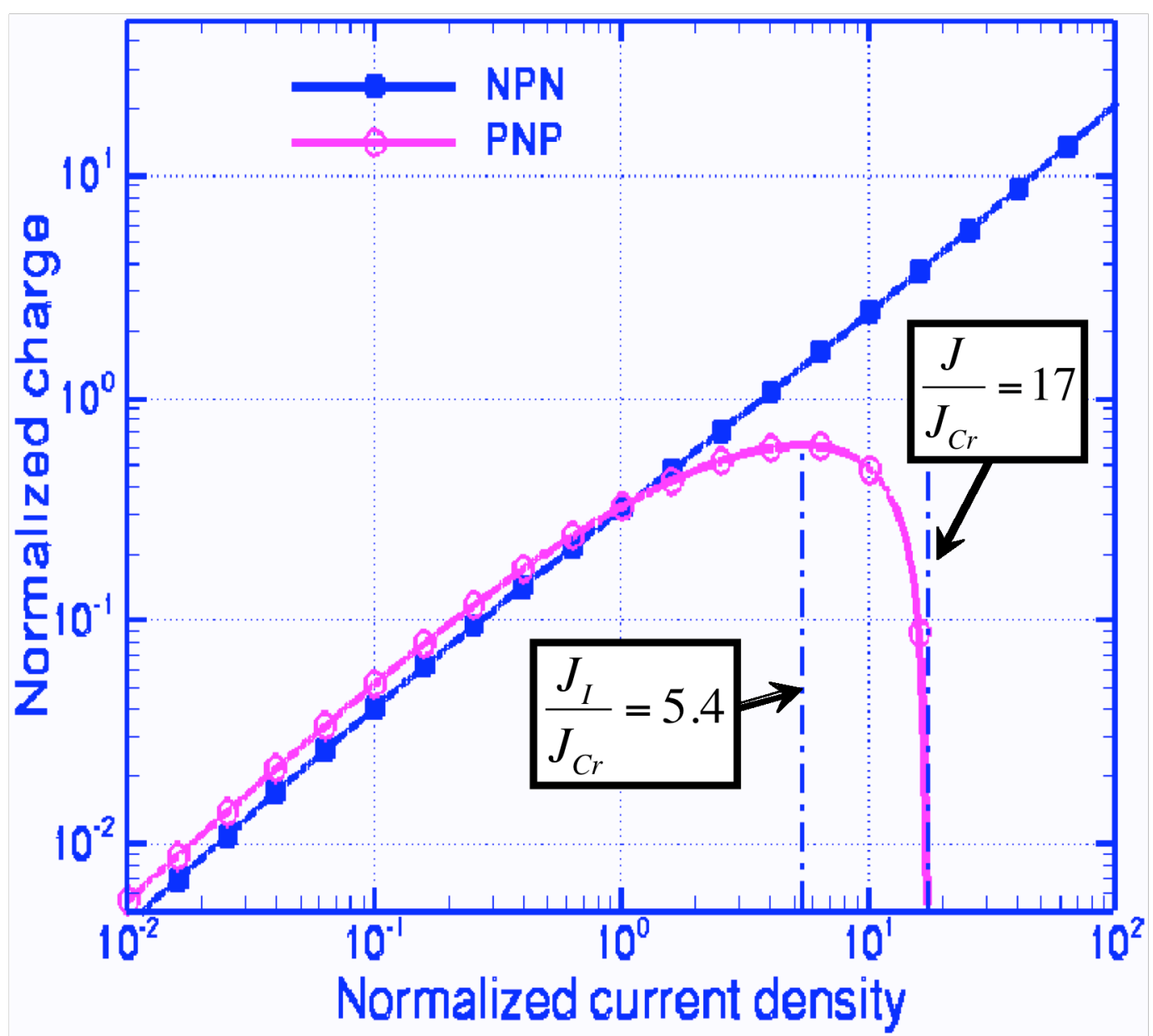

Figure 3: Normalized charge $\left(\rho_{\mathrm{SCR}} / \rho_{\mathrm{Cr}}\right)$ versus normalized current density $\left(\mathrm{J} / \mathrm{J}_{\mathrm{Cr}}\right)$, plotted for (49)).

The SCR charge in an NPN and a PNP is equivalent as far as the current density is smaller than the critical current $\mathrm{J}_{\mathrm{Cr}}$. For higher values, the charge in an NPN monotonously increases, whereas the charge in a PNP decreases when a threshold current density $\mathrm{J}_{\mathrm{I}}$ is exceeded.

For the NPN transistor, the charge variation results in a continuous SCR narrowing, when the current increases. This SCR narrowing tends to reduce the $\mathrm{R}_{\mathrm{ON}}$, which is beneficial for the performance of ESD protections. Concerning the injection ratio, the related internal base widening leads to a decrease of $\mathrm{J}_{\mathrm{Cr}}$ with current. If $\mathrm{J}_{\mathrm{Cr}}$ is lower or similar to the current density during an ESD stress, the condition $\mathrm{J}_{\mathrm{e}_{-}}>>\mathrm{J}_{\mathrm{Cr}}$ is fulfilled and the value of the injection ratio tends to the mobility ratio.

In the case of a PNP, the charge decrease results in a SCR widening, which has a detrimental impact on the $\mathrm{R}_{\mathrm{ON}}$. Besides, the normalized current density value keeps lower 20 
than seventeen (Figure 3), so that the condition $\mathrm{J}_{\mathrm{e}-}>>\mathrm{J}_{\mathrm{Cr}}$ may not be satisfied. This means the injection ratio value here, may not tend to the mobilities ratio.

For further investigations, numerical applications are now undertaken., both for NPN and PNP transistors.

\section{- NPN}

For the numerical application, the parameters $r_{1}$ and $r_{2}$ are calculated for the values of mobilities and the saturation velocities at $300 \mathrm{~K}$ defined in the section 2 :

$$
\begin{aligned}
& r_{1}=\frac{\mu_{n B}}{\mu_{p B}}=3.0 \\
& r_{2}=\frac{v_{s a t, n}}{v_{s a t, n}+v_{s a t, p}}=0.56
\end{aligned}
$$

The variations of $\rho_{\mathrm{SCR}}$ can be estimated through the derivative of expression (47):

$$
\frac{d \rho_{s c r}}{d J}=\frac{1}{v_{s a t, p}}-\frac{1}{1+r_{1}}\left(\frac{1}{v_{s a t, n}}+\frac{1}{v_{s a t, p}}\right)\left(r_{1}+\frac{J_{C r}}{\sqrt{2\left(1+r_{1}\right) \cdot J_{C r} J+J_{C r}^{2}}}\right)
$$

To evaluate the evolution with the current density, the limits of expression (51) are calculated for $\mathrm{J}<<\mathrm{J}_{\mathrm{Cr}}$ and $\mathrm{J}>>\mathrm{J}_{\mathrm{Cr}}$ :

$$
\begin{gathered}
\left|\frac{d \rho}{d J}\right| \underset{J \ll<J_{C r}}{\longrightarrow} \frac{1}{v_{S a t, n}}=l_{1, n} \\
\left|\frac{d \rho}{d J}\right| \underset{J>>J_{C r}}{\longrightarrow} \frac{1}{\left(1+r_{1}\right)} \cdot\left(r_{1} \frac{1}{v_{S a t, n}}-\frac{1}{v_{S a t, p}}\right)=l_{2 ; n}
\end{gathered}
$$

The ratio of these two limits is: 


$$
\frac{l_{2, n}}{l_{1, n}}=\frac{1}{\left(1+r_{1}\right)} \cdot\left(r_{1}-\frac{v_{S a t, p}}{v_{S a t, p}}\right)=0.44
$$

The slope of the charge increase is approximately reduced by two when the current density increases. However, this should not result in a strong degradation of the ESD protection robustness.

\section{- PNP}

Analytic developments for the PNP are equivalent to those of the NPN by inverting the indexes of holes (p) and electrons (n).

In the case of a PNP transistor, the parameters $r_{1}$ and $r_{2}$ are given by :

$$
\begin{aligned}
& r_{1}=\frac{\mu_{p B}}{\mu_{n B}}=0.33 \\
& r_{2}=\frac{v_{s a t, p}}{v_{s a t, p}+v_{s a t, n}}=0.44
\end{aligned}
$$

To characterize the PNP behavior, the most important parameter is the current density at which the charge begins to decrease. This optimum is reached for $\frac{d \rho_{s c r}}{d J}=0$. Given expression (51), the solution of this equation should verify:

$$
\sqrt{2\left(1+r_{1}\right) \cdot \frac{J}{J_{C r}}+1}=\frac{1}{\left[\left(1+r_{1}\right) \cdot r_{2}-r_{1}\right]}
$$

Equation (55) has only a solution if:

$$
\left(1+r_{1}\right) \cdot r_{2}-r_{1} \geq 0
$$

Using the chosen parameters for the numerical application, it results that this condition is 
fulfilled:

$$
\left(1+r_{1}\right) \cdot r_{2}-r_{1}=0.26 \geq 0
$$

and the solution of equation (55) is given by:

$$
J_{I}=J_{C r} \frac{1-\left(\left(1+r_{1}\right) \cdot r_{2}-r_{1}\right)^{2}}{2\left(1+r_{1}\right) \cdot\left[\left(1+r_{1}\right) \cdot r_{2}-r_{1}\right]^{2}}=5.40 J_{C r}
$$

To characterize the PNP behavior, it is also important to determine the injection ratio at extremely high current. As we have to consider that the total charge present in the SCR remains positive:

$$
\rho_{c s r}=\frac{J_{h+}}{v_{s a t, p}}-\frac{J_{e-}}{v_{s a t, n}}>0
$$

a new condition on the injection ratio can be defined:

$$
\gamma=\frac{J_{h+}}{J_{e-}} \geq \frac{v_{s a t, p}}{v_{s a t, n}}
$$

For a PNP, the ratio of the saturation velocities $(\approx 0.8)$ is greater than the ratio of mobilities $(\approx 0.33)$, and hence is the limit of the injection ratio. This physical behavior results from the effect of the base narrowing that induces an increase of the carrier gradient into the base. As a consequence, the diffusion current remains significant compared to the drift current. Therefore, the current induced charge within the base $\mathrm{Q}_{\mathrm{SB}}$ never becomes dominant compared to the doping charge within the emitter $\mathrm{Q}_{\mathrm{E}}$. The maximum ratio of the drift current to the diffusion current can be determined from the following generic expression: 


$$
\frac{J_{\text {Drift }}}{J_{\text {Diffusion }}}=\left|\frac{1}{V_{T}} \cdot \frac{p E}{\frac{d p}{d x}}\right|
$$

Where $\mathrm{V}_{\mathrm{T}}$ is the thermodynamic potential. From the continuity equations (11) and (12) where, under high injection conditions $\mathrm{n}=\mathrm{p}$, we obtain:

$$
\frac{J_{h+}}{J_{e-}}=\frac{\mu_{p B}}{\mu_{n B}} \frac{\left(p E-V_{T} \frac{d p}{d x}\right)}{\left(p E+V_{T} \frac{d p}{d x}\right)}
$$

Given this injection ratio expression, the condition (59) becomes:

$$
\frac{J_{\text {Drift }}}{J_{\text {Diffusion }}} \leq \frac{\frac{v_{s a t, p} \mu_{n B}}{v_{\text {sat }, n} \mu_{p B}}+1}{\frac{v_{\text {sat }, p} \mu_{n B}}{v_{\text {sat }, n} \mu_{p B}}-1}=2.4
$$

This condition means that, in a PNP bipolar transistor, the drift current cannot exceed $70 \%$ of the total current. By contrast, in an NPN one, the drift current can become negligible under very high injection.

\section{Comparison with numerical simulation}

To validate the proposed analytical description, we have compared it to $1 \mathrm{D}$ finite elements simulation results obtained with ISE ${ }^{\circledR}$ simulation tool. The simulated devices are an NPN and a PNP with the same dimensions and doping types simply inverted to switch from NPN to PNP. As for the analytical approach, the doping levels are constant and the junctions abrupt. Besides, carriers' recombination is neglected. The dimensions and doping level are chosen in the same range as the ones used for a high voltage ESD protection in smart power technology. 
An emitter width of $0.25 \mu \mathrm{m}$, a base width of $3 \mu \mathrm{m}$ and a collector width of $1 \mu \mathrm{m}$ are chosen. The emitter, base and collector doping levels are $10^{18} \mathrm{~cm}^{-3}, 10^{16} \mathrm{~cm}^{-3}$ and $10^{20} \mathrm{~cm}^{-3}$, respectively. With these parameters, the maximum gain will be high, resulting in important dynamic fluctuations. To avoid any interference of very high injection effects with thermal effects, the simulations are carried out under isothermal conditions that properly reflect the thermal conditions under very fast ESD pulses.

\section{a. NPN}

The simulations are performed for current densities from $10^{4} \mathrm{~A} \cdot \mathrm{cm}^{-2}$, at which the high injection assumption is valid, up to $10^{6} \mathrm{~A} \cdot \mathrm{cm}^{-2}$, which is the maximum reached in an ESD protection. The effective base widths $\mathrm{W}_{\mathrm{B}}$ are extracted and the critical current densities $\mathrm{J}_{\mathrm{Cr}}$ (23) are calculated, for several current densities (Figure 4). As expected, they increase monotonously. Since the order of magnitude of the critical current density is $10^{4} \mathrm{~A} . \mathrm{cm}^{-2}$, the asymptotic behavior should be reached before the end of the simulation at $10^{6} \mathrm{~A} \cdot \mathrm{cm}^{-2}$.

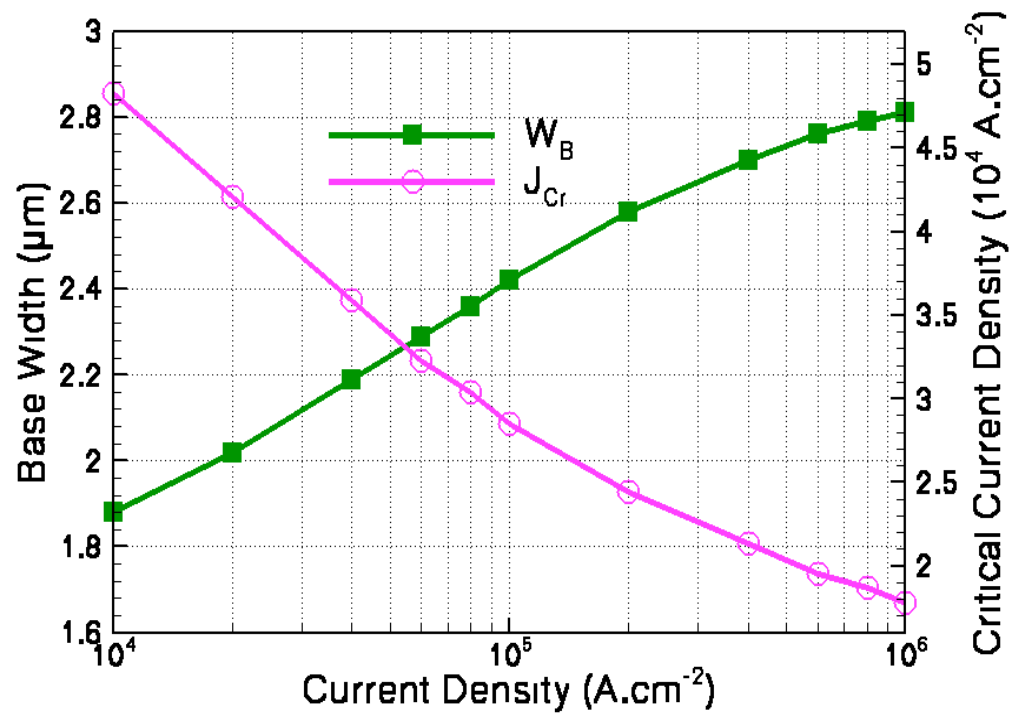

Figure 4: Effective base width $\left(W_{B}\right)$ and critical current density $\left(J_{C r}\right)$ versus the total current density, for an NPN.

The electron and hole current densities within the base are extracted to determine the injection ratio (Figure 5). At high current densities, its value tends to the mobility ratio, as 
predicted by (30). Then, the injection ratio is calculated with the expressions (26), in which $\mathrm{Q}_{\mathrm{SE}}$ is neglected, and (38), in which $\mathrm{Q}_{\mathrm{SE}}$ is taken into account considering high injection in the emitter (Figure 5). The agreement with the simulation is acceptable, in particular at high current densities where the assumptions made are completely fulfilled. Besides, the effect of $\mathrm{Q}_{\mathrm{SE}}$ results in a slight variation that can be neglected.

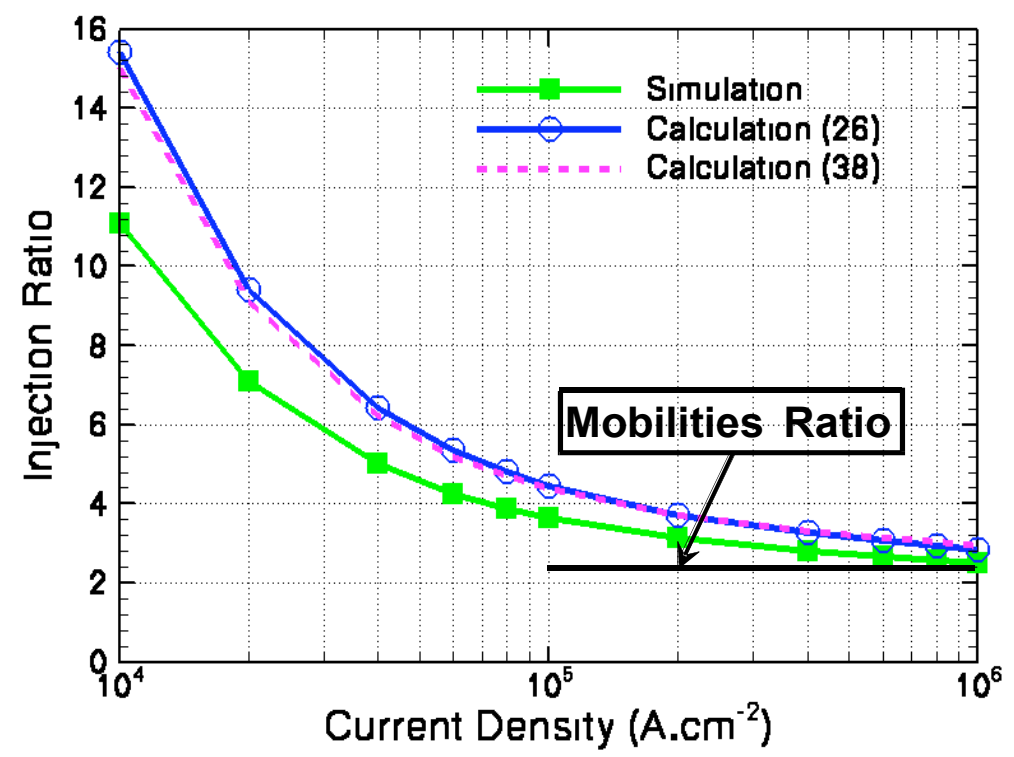

Figure 5: Injection ratio versus current density, obtained from simulation and analytical expressions (26) and (38).

For the proposed analytical description, the mobilities are considered constant in the quasineutral base region, even if they rapidly decrease in a very narrow region closed to the basecollector SCR. This approximation may explain the difference between the simulated and calculated injection ratios.

\section{b. PNP}

The analytical expressions obtained for the NPN will be used as reference, keeping in mind that electron and hole indexes have to be inverted to obtain the expression for the PNP.

The simulations are performed from $10^{3} \mathrm{~A} \cdot \mathrm{cm}^{-2}$, from which the high injection assumptions become valid, and up to $210^{5} \mathrm{~A} \cdot \mathrm{cm}^{-2}$, above which the approximation on the electric field gradient does not remain valid. As for the NPN, the effective base widths $\mathrm{W}_{B}$ and the critical 26 
current densities $\mathrm{J}_{\mathrm{Cr}}$ (23) are calculated for several current densities (Figure 6). As theoretically predicted, a base narrowing is observed at high current. The comparison of the electric field profiles before and after the occurrence of this base narrowing effect (Figure 7) shows a gradient reduction, hence a reduction of the charge, resulting in a SCR extension increase. Using expression (57), we predict that this behavior occurs at a current density of 4.1 $10^{4} \mathrm{~A}^{\mathrm{cm}} \mathrm{cm}^{-2}$. This is in good agreement with the simulation results. To support the optimization of PNP-based ESD protection structures, we can then use this expression to avoid detrimental base narrowing effect on the $\mathrm{R}_{\mathrm{ON}}$.

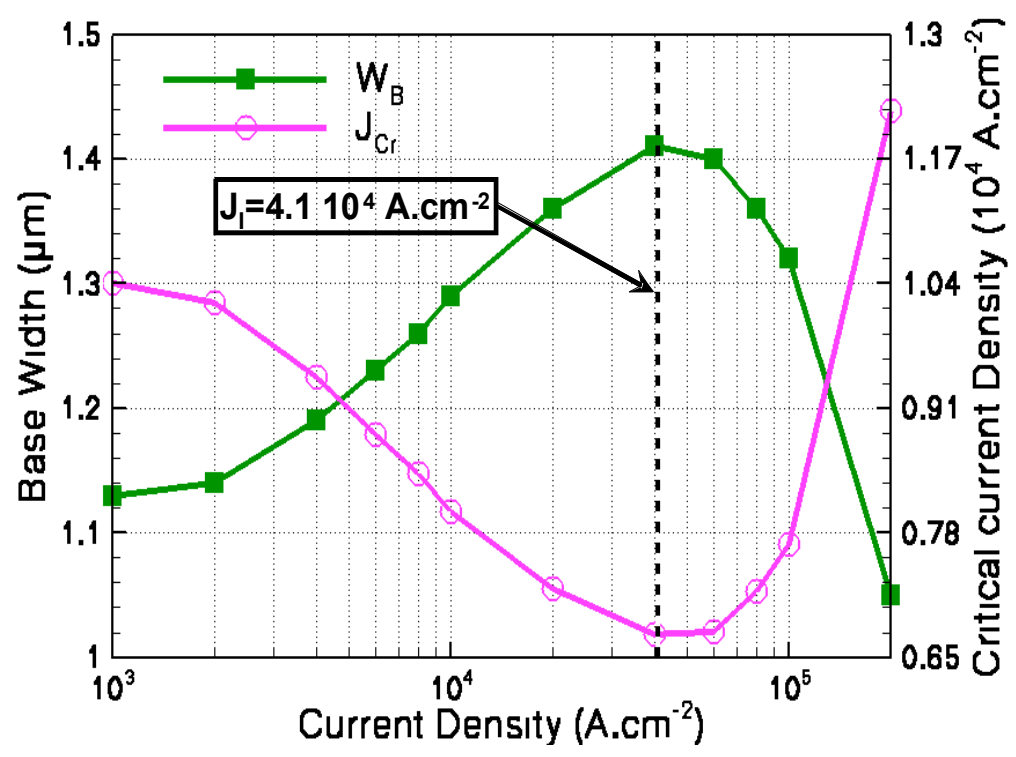

Figure 6: Effective base width $\left(W_{B}\right)$ and critical current density $\left(J_{C r}\right)$ versus the total current density, for a PNP. The calculated current density $J_{I}$, where the base variation changes, is pointed out. 


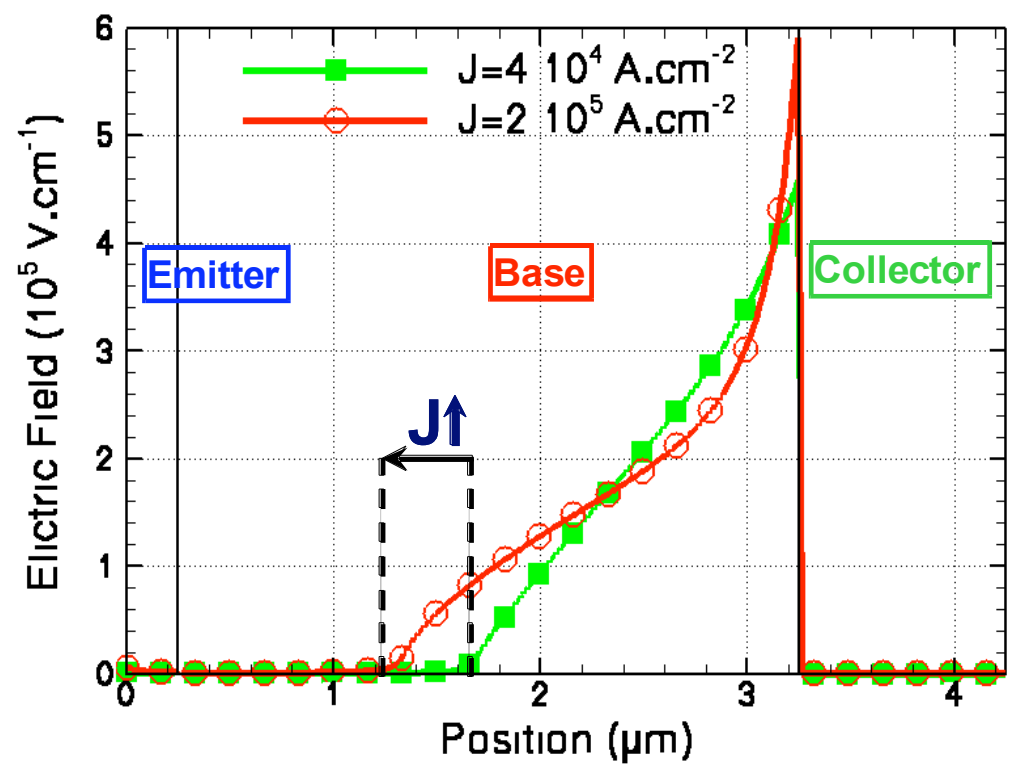

Figure 7: Electric field profiles at current densities 4104 A.cm-2 (maximum internal base extension) and $210^{5}$ A.cm ${ }^{-2}$ (significant base narrowing).

As for the NPN, the injection ratio is directly calculated from the electron and hole current densities and theoretical expressions (26) and (38) (Figure 8). In accordance with (59), its value does not tend to the mobilities ratio, but to the saturation velocity ratio. This confirms the difference between the behaviors of NPN and PNP at extremely high current densities. Above $410^{3}$ A.cm ${ }^{-2}$, the accuracy of the analytical expression is acceptable compared to the direct calculation of ratio between hole and electron current densities.

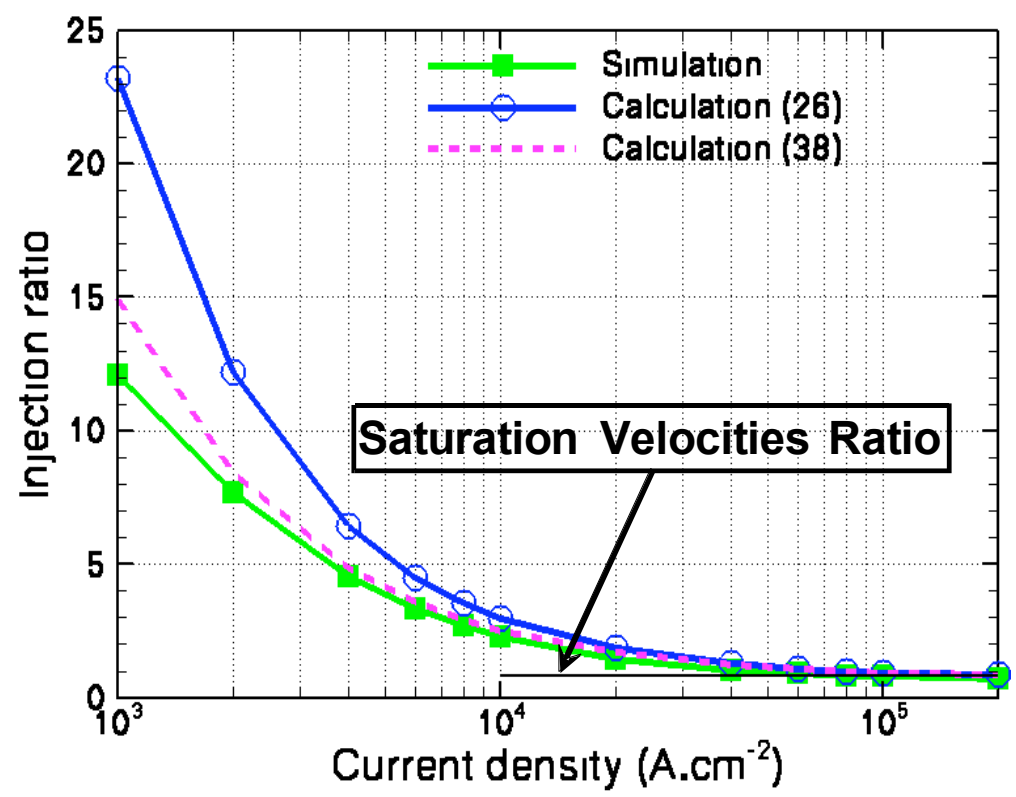

Figure 8: Injection ratio versus current density, obtained directly for the simulation and from the analytical expressions (26) and (38). 


\section{Hypothesis Discussion}

This study of the injection ratio under very high injection was possible by the virtue of some hypothesis. The most limiting ones are the 1D approach with floating base and the isothermal boundaries. For both of them, the discrepancy with the actual behavior of an ESD protection will be qualitatively evaluate. This complementary study is mandatory to determine how accurate are the results of the analytical derivation.

\section{a. 1D description}

As a constraint of the 1D description, the base has to be floating, although it is usually connected to the emitter in self-biased bipolar transistors. Nevertheless, at very high current, this hypothesis is not restrictive as the current flowing to the base contact become negligible compared to the current flowing through the emitter contact. More precisely, the ratio of the avalanche-generated carriers collected at the base contact on those assuring the reverse injection at emitter-base junction tends to zero [14]. In an ESD protection, the only purpose of the base contact is to provide a control on the trigger voltage $V_{t 1}$ [15] and the standby leakage current.

The 1D description assumes that the paths followed by the bias current and by the emitter injection current are the same. This hypothesis is valid for most of the self-biased ESD protections, in which the bias current is generated by the avalanche multiplication of the carriers injected by the emitter (this ensures the maximum of the impact ionization is located along the injection current path) [16] [17]. In particular, this hypothesis is valid for the widely-used vertical NPN transistors. In this type of component, the emitter, the base and the collector are respectively formed by a shallow high-doped $\mathrm{N}$ diffusion, a P-well and a $\mathrm{N}$ buried layer (NBL) biased via a deep N-well (Figure 9). If the distance between the emitter and the NBL is shorter than the distance between the emitter end the deep N (i.e. the vertical 
base is shorter than the lateral base), the electrons injected by the emitter flow vertically under the emitter. Besides, the high avalanche region is located at the P-well-NBL junction so that, the bias current flow vertically from this junction to the emitter.

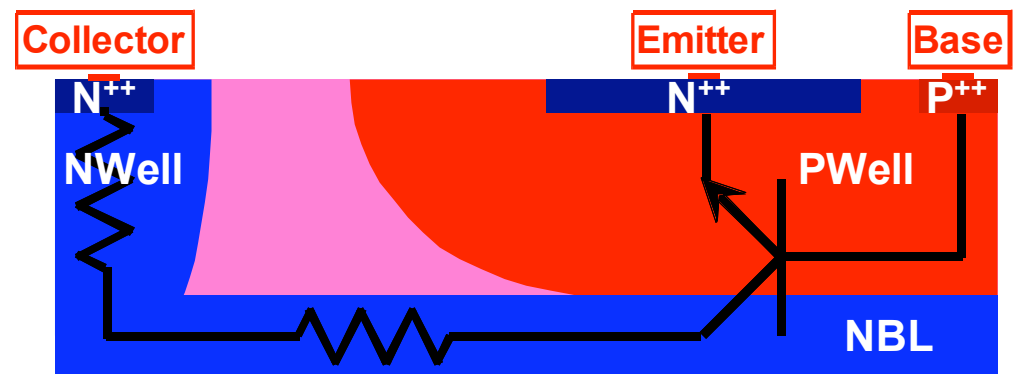

Figure 9: Cross-section of a vertical NPN transistor.

It is important to notice the 1D hypothesis restricts the study to the case of the self-biased transistor. The results cannot be extended to the more general case where the bias current is directly provided at the base contact. For this latter case, the base contact is required, and the bias current does not follow the same path as the emitter injection current. The bias current comes from the base contact whereas the emitter injection current flows toward the basecollector junction.

\section{b. Isothermal condition}

Besides the very high injection conditions, one of the major specificities of an ESD protection is its strong self-heating. The main limitation in the reduction of the protection's size is the temperature, which could be high enough to lead to a second breakdown (between $700 \mathrm{~K}$ and $1250 \mathrm{~K}$ depending on the structure) [18]. This second breakdown induces current filaments where the temperature sharply increases up to the melting point of the silicon and the degradation of the protection [14]. The protection's behavior is influenced by these temperature variations through the modifications of the silicon physical parameters. For the injection ratio of a self-biased bipolar transistor, the most important parameters are the mobility, the saturation velocity (both involved at very high currents), and the impact 
ionization coefficient (as the bias current is provided by an avalanching junction).

\section{- Mobility and saturation velocity}

Both the mobility and the saturation velocity decrease when the temperature increases. At $600 \mathrm{~K}$, their values are typically equal to:

$$
\begin{aligned}
& \mu_{n B}=310 \mathrm{~cm}{ }^{2} \cdot \mathrm{s}^{-1} \cdot \mathrm{V}^{-1} \\
& \mu_{p B}=120 \mathrm{~cm} \cdot \mathrm{s}^{2} \cdot \mathrm{V}^{-1} \\
& v_{\text {sat }, n}=5.8510^{6} \mathrm{~cm} \cdot \mathrm{s}^{-1} \\
& v_{\text {sat }, p}=5.8510^{6} \mathrm{~cm} \cdot \mathrm{s}^{-1}
\end{aligned}
$$


These variations does not modify the analytical expression of the injection ratio limits, (30) for an NPN and (59) for a PNP, as the ratio of the electrons mobility to the holes one (based on the model proposed by Arora and al [19]) remains higher than the ratio of the electrons saturation velocity to the holes one (based on the model proposed by Canali and al. [20]) for the validity range of these models up to $600 \mathrm{~K}$ (Figure 10). As a result, the physical effects described in this paper remain valid, in particular the base narrowing for a PNP. Only the values of the injection ratio limits are modified. At $600 \mathrm{~K}$, these limits are equal to 2.6 for an NPN and 1.0 for a PNP. These values remain close to those at $300 \mathrm{~K}$, corresponding to variations of respectively $13 \%$ and $25 \%$.

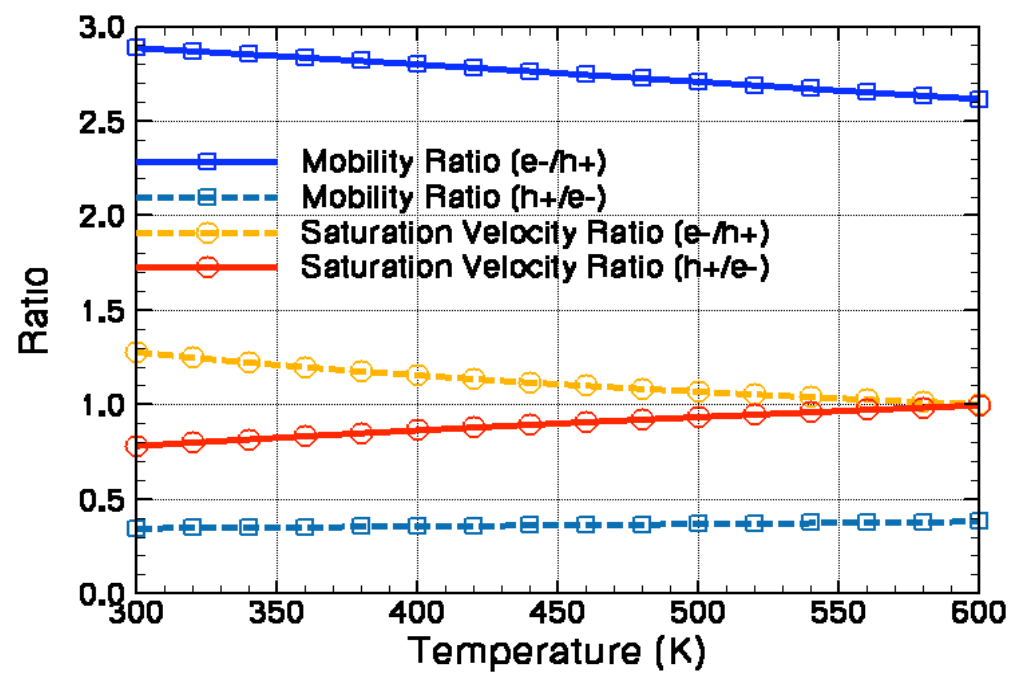

Figure 10: Electrons to holes mobilities and saturation velocities ratio, and vice versa.

\section{- Impact ionization coefficient}

In an ESD protection, the avalanche phenomenon is strongly influenced by the temperature, as it is located in a region where both the current density and the electric field are high and as a result, the heat generation is also high. The amount of carriers generated by avalanche depends on the impact ionization coefficients, which decrease when the temperature increases, for both electrons and holes [21]. To maintain the avalanche current required to 
bias the bipolar transistor, the electric field maximum should increase. This effect tends to widen the base-collector SCR, and hence to reduce the effective base width, whatever the transistor type, NPN or PNP. The consequence on the I-V characteristic of the protection is a $\mathrm{R}_{\mathrm{ON}}$ degradation. To counteract this degradation and to obtain a low- $\mathrm{R}_{\mathrm{ON}}$ protection, it is mandatory to optimize the design of the structure so as to limit or delay the effects leading to the base narrowing.

In the case of an NPN, this optimization can be achieved by strongly decoupling the avalanche injection from the bipolar current gain mechanism that will tend to induce current filamentation and local heating [16]. Such decoupling can be obtained by designing a very wide base bipolar transistor. Using such design guidelines, it was shown that introducing a deep trench into the base to widen it, allows meeting a very high robustness $(>8 \mathrm{kV} H B M)$ together with a very low- $\mathrm{R}_{\mathrm{ON}}(>>1 \Omega)$ [24]. In the case of a PNP, since this base narrowing effect is much more detrimental and current gain cannot be degraded since already very low, the efficient design approach consists in tuning the base and collector doping profiles so as to enhance the space charge region narrowing under very high injection. The proposed analytical model was used to support the design of high voltage PNP-based ESD protection structures before running TCAD simulations. Similarly to NPN-based protections, these structures exhibited a very high ESD robustness $\left(>10 \mathrm{kV}\right.$ HBM) and a greatly improved $\mathrm{R}_{\mathrm{ON}}$ (4 times) that allowed significantly reducing the ESD protection area of high voltage I/Os in an advanced smart power technology [8].

\section{Conclusion}

An analytical description of the current injection ratio of a self-biased bipolar for very high current densities such as encountered during an ESD event have been successfully derived. It 
demonstrates that the decrease of the injection ratio under very high injection conditions has an asymptotic limit that is almost independent on the transistor doping level and dimensions. It is also shown that this limit is equal to the ratio of the mobilities for the case of an NPN transistor and to the ratio of the saturation velocities for the PNP. This asymptotic behavior is reached when the induced current charge within the base becomes in the range of the emitter doping level (for instance a current density of $10^{5} \mathrm{~A} . \mathrm{cm}^{-2}$ in the quasi-neutral base region leads to a carrier concentration of $10^{18} \mathrm{~cm}^{-3}$ ). At such high current density levels, the drift current within the base becomes greatly significant, which is not the case at standard low current levels. Moreover, the expression of the injection ratio allows determining the current induced charge within the base-collector charge space region and then anticipating the influence of such injection levels on the effective SCR and base widths. By this way, we have demonstrated that under very high injection conditions, in contrast to the NPN transistor, the PNP transistor is subjected to a base narrowing effect (inversion of the standard "base pushout"). This effect is reported for the first time. The results of this analytical approach were fully validated by a comparison with numerical simulation. Finally, the discussion of the most restrictive hypothesis, the $1 \mathrm{D}$ analysis and the isothermal conditions, has shown that our conclusions should remain valid for an actual ESD protection.

Besides, this analytical study allows explaining several specificities in the development of ESD protection. Despite the fall of the bipolar gain under high injection, the ESD designers do not optimize their protections to reduce this effect. Sometimes, they even use very low gain transistors. Such approaches are efficient because ESD protections are mainly based on self-biased bipolar transistors. In this configuration, the limit of the injection ratio at high current allows preserving the bipolar effect. This is a major difference compared to others domains of the electronics, such as applications for power management or high frequency. In these applications, the transistors are biased in a regular configuration (bias current provided 34 
through the base contact), and the designers have often to work very hard to keep a high gain value under high injection. Another specificity in the field of ESD is the lack of interest in PNP transistors. The few publications about PNP transistors usually conclude on poor ESD capabilities due to a high $\mathrm{R}_{\mathrm{ON}}$ or a low robustness [22] [23]. These observations may be in relation with the modification of the base-collector SCR in a PNP, which is detrimental for the $\mathrm{R}_{\mathrm{ON}}$, in particular if it leads to a base narrowing. The low robustness can be a direct consequence of a high $\mathrm{R}_{\mathrm{ON}}$, as a higher voltage drop across the protection results in higher energy dissipation. To develop PNP-based ESD protection, it is mandatory to apply specific design rules in order to reduce the effects of the high injection on the base-collector SCR. Based on this thorough analysis of very high injection effects, specific ESD design guidelines were withdrawn and successfully applied to the design of very efficient and robust PNP-based ESD protections.

\section{Bibliography}

[1] C. T. Kirk,"A theory of transistor cutoff frequency (fT) falloff at high current densities", IRE Trans. on electron devices, pp 164-173, 1961.

[2] Markus P.J. Mergens, Michael T. Mayerhofer, Joost A. Willemen, Matthias Stecher, "ESD Protection Considerations in Advanced High-Voltage Technologies for Automotive", in Proc. EOS/ESD Symposium, September 2006, pp54-63.

[3] M. Mergens, W. Wilkening, S. Mettler, H. Wolf, A. Stricker, W. Fichtner, "Analysis and Compact Modeling of Lateral DMOS Power Devices under ESD Stress Conditions", in Proc. EOS/ESD Symposium, September 1999, pp1-10.

[4] V. De Heyn, G. Groeseneken, B. Keppens, M. Natarajan, L. Vacaresse, G. Gallopyn, "Design and Analysis of New Protection Structures for Smart Power Technology with Controlled Trigger and Holding Voltage", in Proc. IRPS, pp. 253-258, 2001.

[5] G. Bertrand, C. Delage, M. Bafleur, N. Nolhier, J.M. Dorkel, Q Nguyen, N. Mauran, D. Trémouilles, P. Perdu, "Analysis and Compact Modeling of a Vertical Grounded-Base n-p-n Bipolar Transistor Used as ESD Protection in a Smart Power Technology", Solid State Circuits, vol. 36, n 9 , pp. 1373-1381, September 2001.

[6] M-D. Ker, K-H. Lin, "Double Snapback Characteristics in High-Voltage nMOSFETs and the Impact to On-Chip ESD Protection Design", IEEE Electron Devices Letters, vol. 25, n 9, September 
[7] K. Reynders, V. De Heyn, M. Zubeidat, "Electrostatic Discharge Protection Device", European Patent Application EP1482554A1, December 2004.

[8] A. Gendron, P. Renaud, P. Besse, C. Salamero, M. Bafleur, N. Nolhier, "Area-Efficient Reduced and No-Snapback PNP-based ESD Protection in Advanced Smart Power Technology", in Proc. EOS/ESD Symposium, pp. 69-76, Sep. 2006.

[9] P. Renaud, A. Gendron, M. Baflaur, N. Nolhier, "Efficient High Voltage No-Snapback and Low Ron ESD Protection Device for Smart Power Technologies", in Proc. International Electrostatic Discharge Workshop, May 2007.

[10] W.M. Webster, "On the Variation of Junction-Transistor Current-Amplification Factor with Emitter Current", Proceedings of the IRE, June 1954, pp. 914-920.

[11] E.S. Rittner, "Extension of the Theory of the Junction Transistor", Physical Review, vol. 94, $\mathrm{n}^{\circ} 5$, June 1954, pp. 1161-1171.

[12] G. Rey, J.P. Bailbé, "Some Aspects of Current Gain Variations in Bipolar Transistors", SolidState Electronics, vol. 17, 1974, pp. 1045-1057.

[13] J.P. Bailbé, "Contribution à l'Etude Physique des Transistors Bipolaires”, State Doctorate Thesis, $n^{\circ} 744$, Paul Sabatier University, Toulouse (France), February 8, 1977.

[14] K. Esmark, "Device Simulation of ESD Protection Elements", Series in Microelectronics, vol. 128, ISBN 3-89649-781-2, 2002.

[15] A. Amerasekera, A. Chatterjee, "An Investigation of BiCMOS ESD Protection Circuits Elements and Applications in Submicron Technologies", in Proc. EOS/ESD Symposium, pp. 265-276, 1992.

[16] D. Tremouilles, G. Bertrand, M. Bafleur, N. Nolhier, L. Lescouzeres, "Design Guidelines to Achieve a Very High ESD Robustness in Self-Biased NPN", in Proc. EOS/ESD Symposium, pp. 281288, September 2002.

[17] N. Jensen, G. Groos, M. Denison, J Kuzmik, D. Pogany, E. Gornik, M. Stecher, "Coupled Bipolar Transistors as Very Robust ESD Protection Devices for Automotive Applications", in Proc. EOS/ESD Symposium, pp. 313-318, Sept. 2003.

[18] A. Amerasekera, M-C. Chang, A. Seitchik, A. Chatterjee, K. Mayaram, J-H. Chern "Self-Heating Effects in Basic Semiconductor Structures", IEEE transactions on Electron Devices, vol. 40, $\mathrm{n}^{\circ} 10$, October 1993.

[19] N.D. Arora, J.R. Hauser, D.J. Roulson, "Electron and Hole Mobilities in Silicon as Function of Concentration and Temperature", Solid State Circuit, vol. 36, n 9, pp 1373-1381, September 2001.

[20] C. Canali, G. Majni, R. Minder, G. Ottaviani, "Electron and Hole Drift Velocity Measurement in Silicon and their Empirical Relation to Electric Field and Temperature", IEEE Transaction on Electron Devices, vol. 35, n5, pp. 1045-1047, 1075.

[21] S. Reggiani, E. Gnani, M. Rudan, G. Baccarani, C. Corvasce, D. Barlini, M. Ciappa, W. Fichtner, M. Denison, N. Jensen, G. Groos, M. Stecher, "Experimental extraction of the electron impactionization coefficient at large operating temperatures", in IEDM technical digest, pp 407-410, 2004. 
[22] M-D. Ker, K-H. Lin,"The Impact of Low-Holding-Voltage and the Design of Latch-up Free Power-Rail ESD Clamp Circuit for LCD Drivers Ics", IEEE Journal of Solid State Circuit, vol. 40, ${ }^{\circ}$ 8, pp1751-59, August 2005.

[23] J. Li, R. Gauthier, K. Chatty, D. Kontos, M. Muhammad, M. Woo, C. Putman, C. Russ, D. Alvarez, J. Schneider, P.T. Tan, "PMOSFET-based ESD Protection in $65 \mathrm{~nm}$ Bulk CMOS Technology for Improved External Latchup Robustness", in Proc. EOS/ESD Symposium, pp. 407-412, September 2005.

[24] A. Gendron, C. Salamero, N. Nolhier, M. Bafleur, P. Renaud, P. Besse, Deep Trench NPN transistor for Low-RON ESD Protection of High-Voltage I/Os in Advanced Smart Power Technology, Bipolar/BiCMOS Circuits and Technology Meeting (BCTM'2006), Maastritch (Pays-Bas), October 7-10, 2006. 